\title{
The Deformation Behavior, Microstructural Mechanism, and Process Optimization of PM/Wrought Dual Superalloys for Manufacturing the Dual-Property Turbine Disc
}

\author{
Baoyun Zhang, Xiaoming Liu, Hao Yang and Yongquan Ning *(D) \\ School of Materials Science and Engineering, Northwestern Polytechnical University, Xi'an 710072, China; \\ braveryzhang@mail.nwpu.edu.cn (B.Z.); xiaomin76123@mail.nwpu.edu.cn (X.L.); \\ 2018200809@mail.nwpu.edu.cn (H.Y.) \\ * Correspondence: luckyning@nwpu.edu.cn; Tel.: +86-29-8849-2642
}

Received: 27 September 2019; Accepted: 18 October 2019; Published: 21 October 2019

check for updates

\begin{abstract}
With the rapid development of modern aviation industry, dual-property turbine disc with fine comprehensive performance plays an important role in raising the thrust-to-weight ratio of the aero-engine. For manufacturing dual-property turbine disc, the powder metallurgy superalloy (PM) with excellent creep resistance was chosen as rim material, and the wrought superalloy with fine equiaxed grains was chosen as bore material. Electron beam welding was carried out on the $\mathrm{PM} /$ wrought dual superalloys. Hot compression tests were conducted on the PM/Wrought dual superalloys at temperatures of $1020-1140{ }^{\circ} \mathrm{C}$ and strain rates of $0.001-1.0 \mathrm{~s}^{-1}$. Deformation behavior and microstructure evolution have been investigated to study the deformation and recrystallization mechanism during hot deformation process. The results showed that PM/Wrought dual superalloy presents the similar flow behavior to single alloys and flow stress decreases significantly with the increase of deformation temperature or the decrease of strain rate. The apparent activation energy of deformation at the strain of 0.2 was determined as being $780.07 \mathrm{~kJ} \cdot \mathrm{mol}^{-1}$. The constitutive equation was constructed for modeling the hot deformation of PM/Wrought dual superalloy. Meanwhile, the processing map approach was further adopted to optimize the manufacturing process for the dual-property turbine disc. Additionally, a new instability criterion was proposed: the "cliff" and "valley" in the power dissipation map are determined as sufficient conditions for flow instability. The optimum processing parameter for manufacturing the PM/Wrought dual-property turbine disc can be obtained to enhance the mechanical properties, based on the analysis of processing map technology and microstructural mechanism.
\end{abstract}

Keywords: PM/Wrought dual superalloy; deformation behavior; microstructural mechanism; process optimization; dual-property turbine disc

\section{Introduction}

Turbine discs are usually the most critical engine components attracting the main research attention in the field of advanced manufacturing. As the major component in advanced aero-engines, the working circumstances of turbine disc are severe and special, owing to the different parts of the disc need to bear different working temperatures and stresses. For turbine disc, high mechanical strength and fatigue resistance are needed for the inner region, which works at a low temperature. Excellent fatigue life and crack growth resistance are required for the outer region, which works at a high temperature [1]. With the rapid development of modern aviation industry, dual-property turbine 
disc with fine comprehensive performance plays an important role in raising the thrust-to-weight ratio of the aero-engine.

Generally, it is an effective and reliable method to fabricate the dual-property turbine disc by welding. Electron beam welding is a useful emerging technology for joining and repairing aero-engine components because it has many advantages, such as small ratio between width and depth, narrow heat affected zone, and little weld thermal deformation [2,3]. During the electron beam welding process for nickel-based superalloys, solidification cracking occurs in the fusion zone. Meanwhile, the heat-affected zone may develop grain boundary liquation micro-fissuring [4]. Both of these outcomes are harmful to the mechanical properties of the electron beam weldments. Therefore, it is of great importance that the hot forging process should be conducted on the electron beam seam to solve the defects and improve the microstructure. Ning et al. [5] investigated the electron beam welding process of Ni-base superalloy GH4133B and found that the welding defects can be eliminated availably by the following hot plastic deformation process conducted on weldments. Qing et al. [6] explored the hot deformation behavior of the TC11/Ti-22Al-25Nb dual-alloy and obtained the optimum processing condition for the electron beam (EB) weldments during the hot working process.

In present research, the powder metallurgy superalloy (PM) with excellent creep resistance was chosen as rim material, and the wrought superalloy with fine equiaxed grains was chosen as bore material. The electron beam welding was carried out on the PM/Wrought dual superalloys. Cylindrical compression specimens were fabricated from the welding seam of the PM/Wrought structure, and then hot compression tests were conducted. Deformation behavior and microstructure evolution were systematically and deeply investigated to study the deformation and recrystallization mechanism under the thermal-mechanical coupling conditions, and processing map approach was further adopted to optimize the manufacturing process for the dual-property turbine disc.

\section{Materials and Methods}

Figure 1 schematically illustrates the main fabrication processes of dual-property turbine disc. Two specimens were machined with the same dimensions of $30 \times 30 \times 6 \mathrm{~mm}$ from as-received nickel-based superalloys. Mechanical polishing was conducted on the specimens to reduce their surface roughness before electron beam welding. The electron beam welding was carried out on the prepared specimens by using a KS55-G150 (IGM, Frankfurt, Germany) with the welding speed at $2 \mathrm{~mm} / \mathrm{s}$. The accelerating voltage was selected as $150 \mathrm{kV}$ and the electron current was $32 \mathrm{~mA}$. The compression specimen with diameter $8 \mathrm{~mm}$ and height $12 \mathrm{~mm}$ was machined from the welding seam of the PM/Wrought dual superalloy, which contains the base metal of PM superalloy, welding seam, and the base metal of wrought superalloy. 


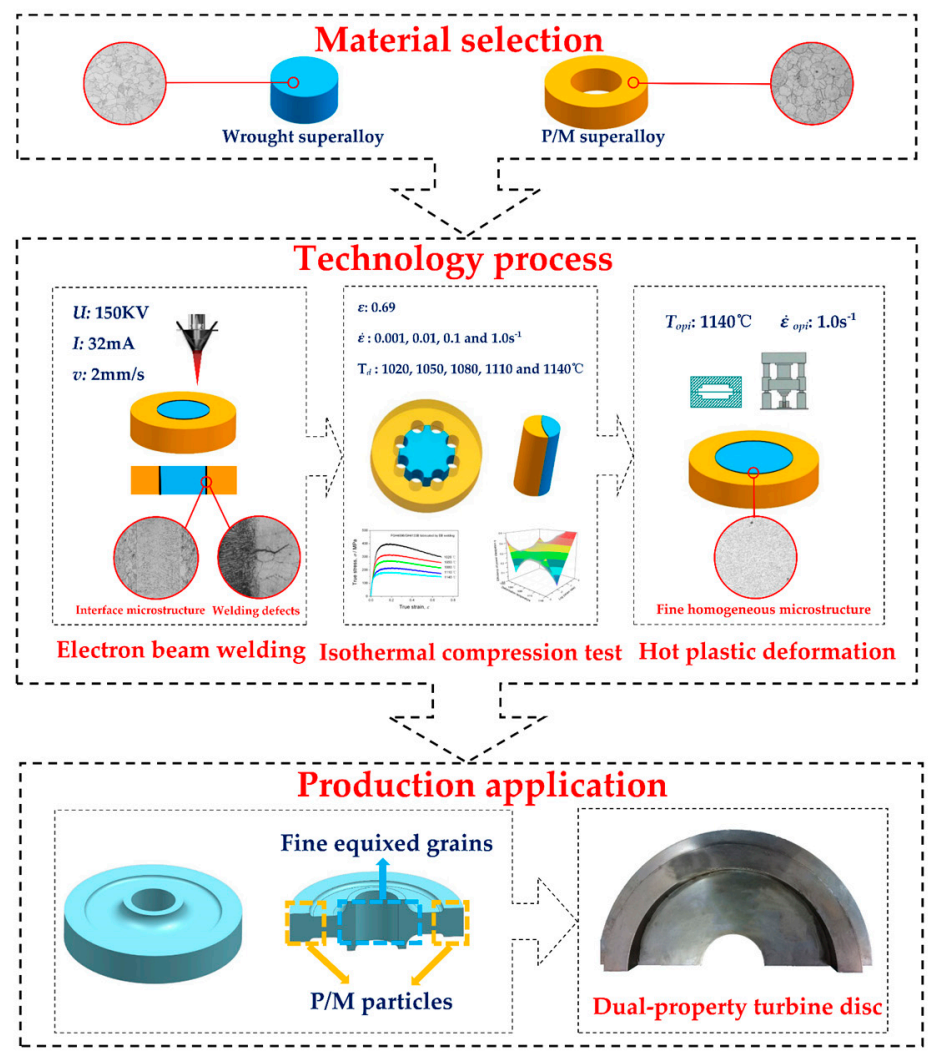

Figure 1. Schematic illustration of the fabrication for dual-property turbine disc in present research.

The isothermal compression tests were conducted using Gleebe-1500D thermo-simulation machine (DSI, America) at different deformation temperatures $\left(1020,1050,1080,1110\right.$, and $\left.1140{ }^{\circ} \mathrm{C}\right)$ and different strain rates $\left(0.001,0.01,0.1\right.$, and $\left.1.0 \mathrm{~s}^{-1}\right)$ with the height reduction selected as $50 \%$. Specimens were heated up to the target temperature with the heating rate of $10^{\circ} \mathrm{C} / \mathrm{s}$ and then maintained for $3.0 \mathrm{~min}$ to achieve homogenize temperature distribution in the entire specimen. The true stress-strain data during the isothermal compression test were collected and recorded automatically. After compression, the deformed specimens were water-quenched instantly to retain the deformed microstructure. Then these specimens were wire-cut along the plane containing compression axis. After being ground and polished, the exposed surfaces were corroded with the chemical etchant of $\mathrm{CuSO}_{4}(10 \mathrm{~g})+\mathrm{H}_{2} \mathrm{O}_{2}(10 \mathrm{~mL})+$ $\mathrm{HCl}(40 \mathrm{~mL})+\mathrm{H}_{2} \mathrm{O}(50 \mathrm{~mL})$. Finally, the microstructure examination of compressed specimens was illustrated by using optical microscope (Olympus, Japan).

The typical microstructure of welding seam for PM/Wrought dual superalloy is given in Figure 2. It can be observed from Figure 2a that PM superalloy reveals previous particle boundaries (PPBs) network and wrought superalloy shows equiaxed microstructure. Meanwhile, there is dendrite microstructure in fusion zone. Therefore, the microstructure distribution at bonding interface of the $\mathrm{PM} /$ Wrought dual superalloy presents three different states, the transition of interfacial microstructure is not uniform. In addition, the optical micrograph at higher magnification shows no boundary between the base metal PM superalloy and the fusion zone (Figure 2b), which indicates that the interface between the previous particle boundary and dendrite is well connected macroscopically and the micro-mechanism deserves further exploration. Remarkably, an obvious boundary between the fusion zone and the base metal wrought superalloy can be seen from Figure 2c. At the interface, there may be some defects, such as micro-cracks, which can cause instability in the weldments, and it is extremely unfavorable for the mechanical properties of the PM/Wrought dual superalloy. 


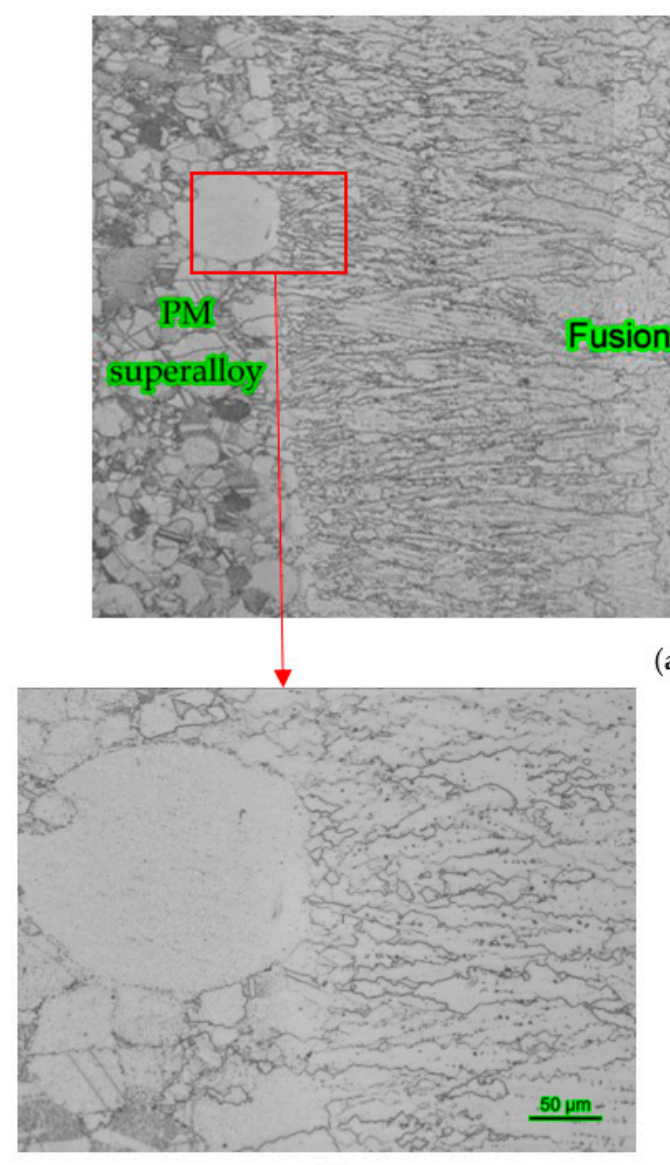

(b)

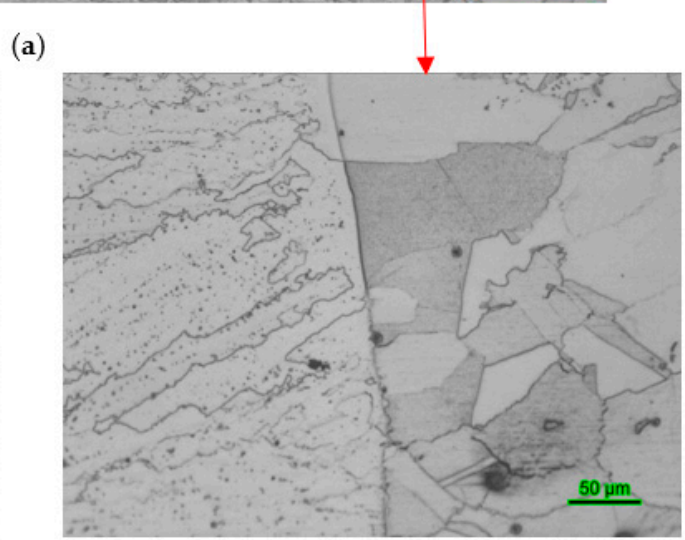

(c)

Figure 2. Typical microstructure of the PM/Wrought dual superalloy. (a) Optical micrograph showing previous particle boundaries (PPBs) network in base metal PM superalloy, dendrite microstructure in fusion zone, and equiaxed microstructure in base metal wrought superalloy; (b) Optical micrograph showing no boundary between PM superalloy and fusion zone at higher magnification; (c) Optical micrograph showing obvious boundary between fusion zone and wrought superalloy at higher magnification.

\section{Results and Discussion}

\subsection{Flow Stress Behavior of PM/Wrought Dual Superalloy}

Figure 3 demonstrates the true stress-strain curves of the PM/Wrought dual superalloy at different isothermal compression test conditions. The deformation temperature and strain rate have a significant effect on the true stress-strain curves, from which the inherent connection between the flow stress and deformation behavior can be systematically studied. The curvilinear trend of all flow stress curves is similar, both of them can be divided into three different parts, which are strain hardening stage, dynamic-softening stage, and relatively steady stage. In the initial stage of hot compression, the flow stress increases rapidly (almost linearly) until a peak value appears due to the generation and multiplication of dislocations, results in obvious strain hardening stage [7]. During the following stage, the flow stress progressively decreases as deformation proceeds. This feature of flow stress is related to the emergence of dynamic softening mechanisms (DRV and DRX) due to the cross-slip and climb of dislocation, which can partially neutralize the effect of strain hardening. At the high-strain zone, with the further accumulation of dislocation density, the DRX behavior is more sufficient and plays the major role in dynamic softening. Finally, the dynamic equilibrium between strain hardening and dynamic softening can be reached, leading to a relatively steady state of flow stress. In addition, it is noteworthy that the value of peak stress is sensitive to the strain rate and deformation temperature. 
At a specific deformation temperature, the peak stress increases following the increase of the strain rate. Under a relatively high strain rate, the shortening of the deformation time not only increases the strain hardening effect but also restrains the nucleation and growth of DRX grains. However, for a fixed strain rate, the peak stress generally decreases with the augmentation of the deformation temperature. As the deformation temperature increases, the kinetic energy of atoms increase due to the enhancement of thermal activation energy. Moreover, the critical cutting stress among atoms controlled through crystal slip decreases. Both of these outcomes lead to lower flow stress [8].

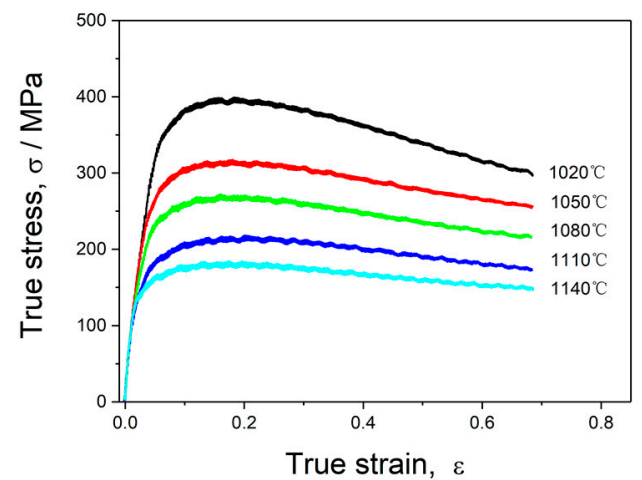

(a)

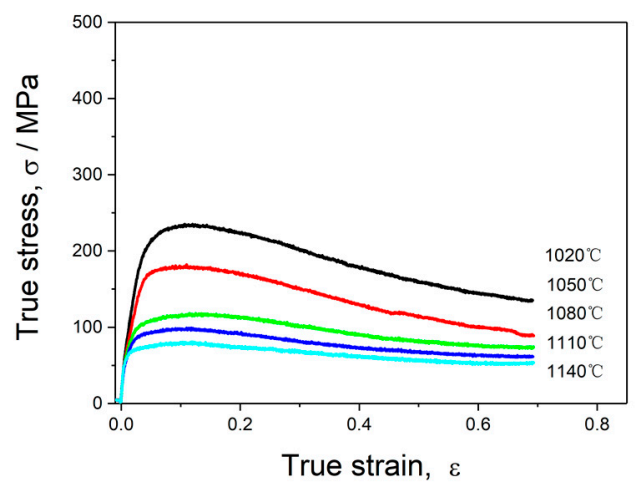

(c)

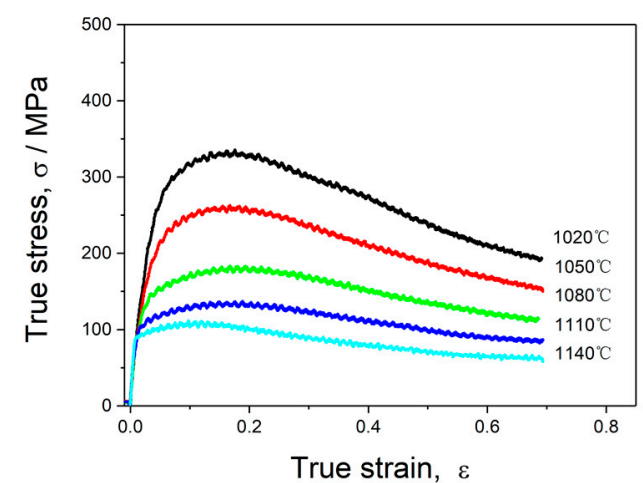

(b)

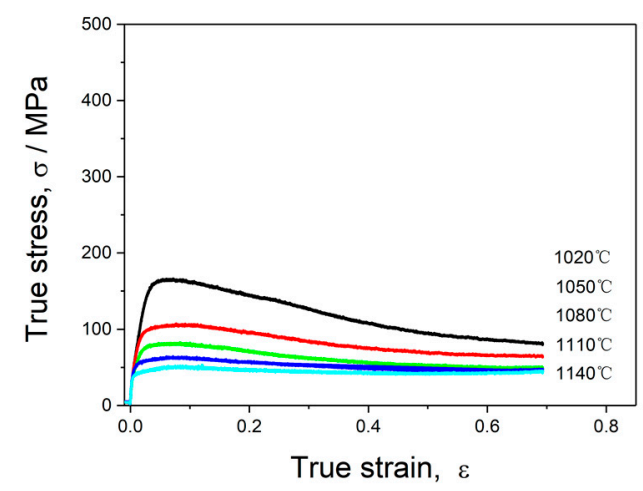

(d)

Figure 3. The true stress-strain curves of the PM/Wrought dual superalloy under different deformation temperatures with strain rates of (a) $1.0 \mathrm{~s}^{-1}$; (b) $0.1 \mathrm{~s}^{-1}$; (c) $0.01 \mathrm{~s}^{-1} ;$ (d) $0.001 \mathrm{~s}^{-1}$.

\subsection{Constitutive Equation of PM/Wrought Dual Superalloy}

Generally, the hot plastic deformation of superalloys can be considered to be a process controlled by thermal activation, which is susceptible to deformation parameters such as true strain, strain rate, and deformation temperature. The constitutive equation, which reveals the intrinsic relationship between the flow stress, deformation temperature, and strain rate, is regarded as an effective approach to describe the flow behavior and predict the flow stress of work-piece during the deformation process. The Arrhenius-type equation, proposed by Sellars and Mctegart [9], which is the most widely applied model and can be denoted as the following:

$$
\dot{\varepsilon}=A f(\sigma) \exp \left(-\frac{Q}{R T}\right)
$$

According to the different level of stress, Equation (1) can be simplified into these forms:

1. When $\alpha \sigma<0.8$, viz., for lower stress,

$$
\dot{\varepsilon}=A_{1} \sigma^{n_{1}} \exp \left(-\frac{Q}{R T}\right)
$$


2. When $\alpha \sigma>1.2$, viz., for higher stress,

$$
\dot{\varepsilon}=A_{2} \exp (\beta \sigma) \exp \left(-\frac{Q}{R T}\right)
$$

3. For all values of $\alpha \sigma$,

$$
\dot{\varepsilon}=A[\sinh (\alpha \sigma)]^{n} \exp \left(-\frac{Q}{R T}\right)
$$

In the above equations, $\dot{\varepsilon}$ is strain rate $\left(\mathrm{s}^{-1}\right) ; \sigma$ is the flow stress $(\mathrm{MPa}) ; T$ is deformation temperature $(\mathrm{K}) ; Q$ is activation energy $\left(\mathrm{kJ} \cdot \mathrm{mol}^{-1}\right) ; R$ is molar gas constant $\left(8.314 \mathrm{~kJ} \cdot \mathrm{mol}^{-1} \cdot \mathrm{K}^{-1}\right)$; Moreover, $A_{1}, A_{2}$, $A, \beta, n, n_{1}$, and $\alpha\left(\alpha=\beta / n_{1}\right)$ are material constants.

In order to identify the above material constants, taking the natural logarithm on both side of Equations (2)-(4) simultaneously:

$$
\begin{gathered}
\ln \dot{\varepsilon}=n_{1} \ln \sigma+\left(\ln A_{1}-\frac{Q}{\mathrm{RT}}\right) \\
\ln \dot{\varepsilon}=\beta \sigma+\left(\ln A_{2}-\frac{Q}{\mathrm{RT}}\right) \\
\ln \dot{\varepsilon}=n \ln [\sinh (\alpha \sigma)]+\left(\ln A-\frac{Q}{\mathrm{RT}}\right)
\end{gathered}
$$

In this research, the true strain of 0.2 is taken as an example to illustrate the calculating procedure of material constants. From Equations (5) and (6), it can be known that $n_{1}=\partial \ln \dot{\varepsilon} / \partial \ln \sigma$ and $\beta=\partial \ln \dot{\varepsilon} / \partial \sigma$. Figure $4 \mathrm{a}, \mathrm{b}$ gives the linear relationship of $\ln \sigma-\ln \dot{\varepsilon}$ and $\sigma-\ln \dot{\varepsilon}$ at different deformation temperatures. Based on the reciprocal of average value of slopes of these fitted lines, the value of $n_{1}$ and $\beta$ can be obtained as 5.584 and 0.037 . Then the $\alpha$-value is determined to be 0.0066 .

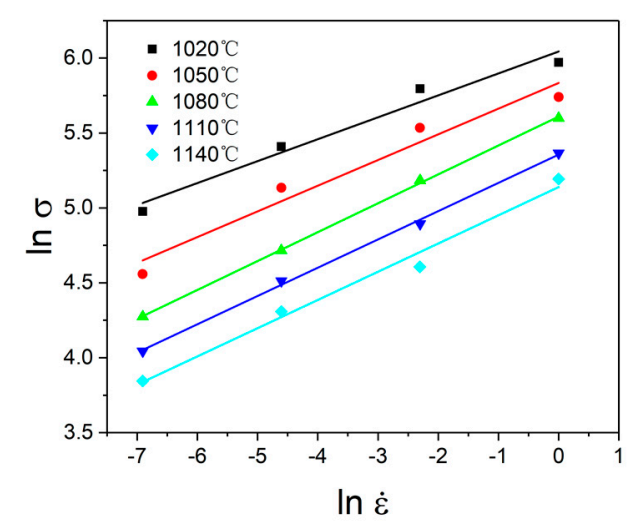

(a)

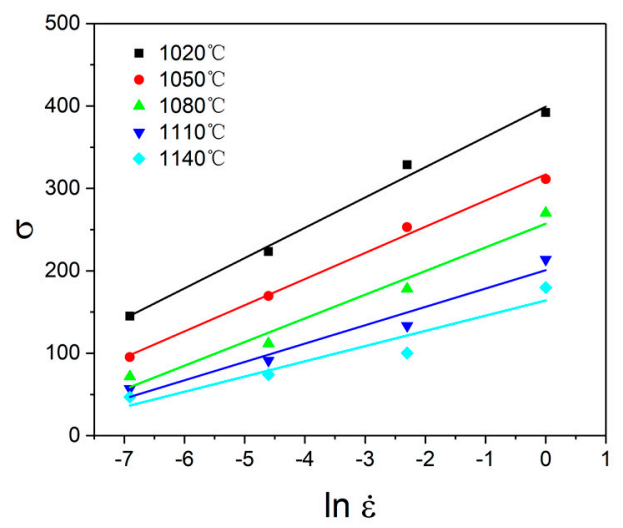

(b)

Figure 4. Relationship of the PM/Wrought dual superalloy between: (a) $\ln \sigma$ and $\ln \dot{\varepsilon}$; (b) $\sigma$ and $\ln \dot{\varepsilon}$.

The partial derivative is taken on both sides of Equation (7) to $\ln [\sin \mathrm{h}(\alpha \sigma)]$. When the deformation temperature is fixed, the following linear relationship can be given:

$$
n=\left.\frac{\partial \ln \dot{\varepsilon}}{\partial \ln [\sinh (\alpha \sigma)]}\right|_{T}
$$

Similarly, when the strain rate is constant, the activation energy $Q$ can be expressed as:

$$
Q=\left.R n \frac{\partial \ln [\sinh (\alpha \sigma)]}{\partial(1 / T)}\right|_{\dot{\varepsilon}}
$$


The linear relationship of $\ln \dot{\varepsilon}-\ln [\sinh (\alpha \sigma)]$ and $\ln [\sinh (\alpha \sigma)]-(1000 / T)$ are obtained, respectively, as shown in Figure 5. From Figure 5a, the average slope of these lines gives the value of $n$ as 4.14. Likewise, the value of $Q / R n$ can be calculated from Figure $5 \mathrm{~b}$. The $Q$-value is derived as $780.07 \mathrm{~kJ} \cdot \mathrm{mol}^{-1}$, and this value is higher than the self-diffusion of nickel $\left(278 \mathrm{~kJ} \cdot \mathrm{mol}^{-1}\right)$ [10], which is attributed to the occurrence of DRX [11].

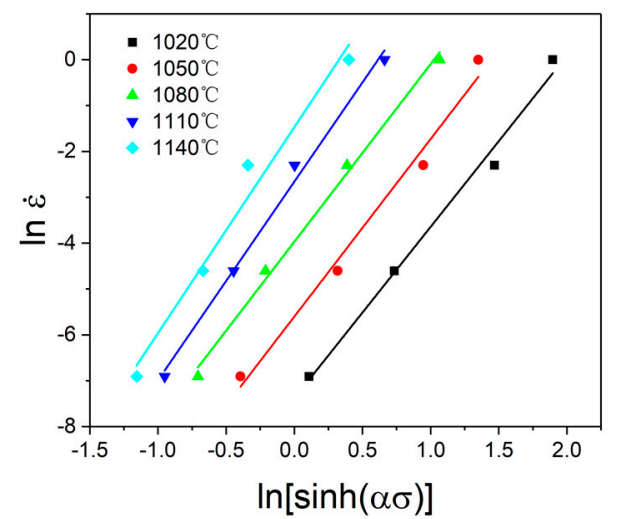

(a)

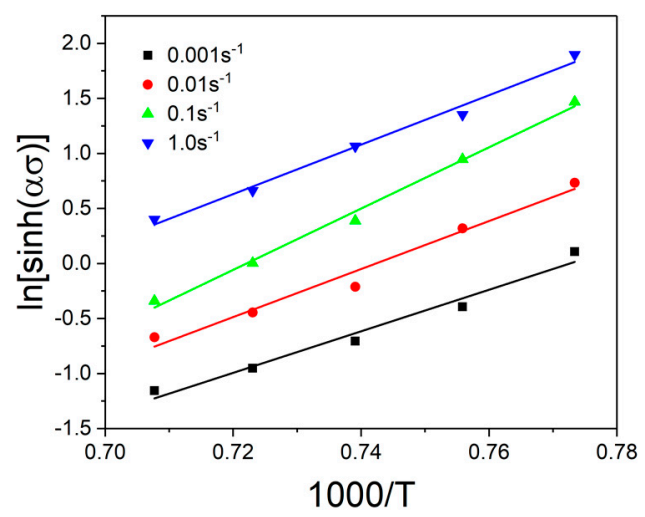

(b)

Figure 5. Relationship of the PM/Wrought dual superalloy between: (a) $\ln \dot{\varepsilon}$ and $\ln [\sinh (\alpha \sigma)]$; (b) $\ln [\sinh (\alpha \sigma)]$ and $(1000 / T)$.

Based on the research of Zener and Hollomon [12], the comprehensive effect of deformation temperature and strain rate on flow stress during the hot plastic deformation process can be expressed by Zener-Hollomon parameter, as shown in following equation:

$$
Z=\dot{\varepsilon} \exp \left(\frac{Q}{R T}\right)
$$

By combining Equations (4) and (10), and then taking the natural logarithm, Equation (11) can be derived as:

$$
\ln Z=\ln A+n \ln [\sinh (\alpha \sigma)]
$$

According to the linear relationship of $\ln Z-\ln [\sinh (\alpha \sigma)]$, Figure 6 can be obtained. Moreover, the correlation coefficient is about 0.99 . The intercept of this line represents the value of $\ln A$, thus the $A$-value is determined as being $2.33 \times 10^{28}$.

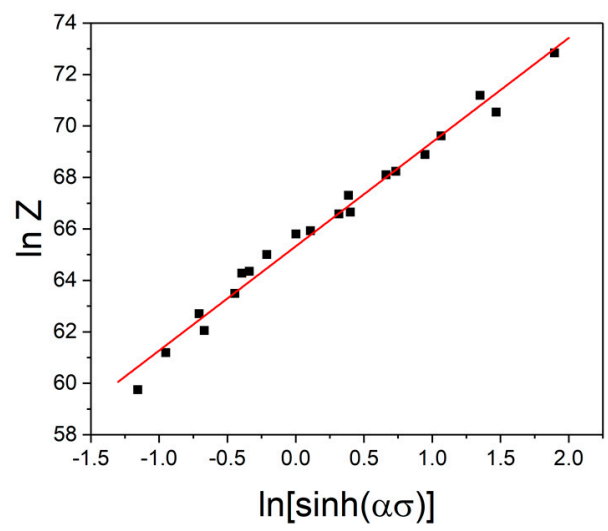

Figure 6. Relationship of the PM/Wrought dual superalloy between $\ln Z$ and $\ln [\sin h(\alpha \sigma)]$. 
On the basis of above analysis, all of the material constants can be obtained. Therefore, the constitutive equation at the strain of 0.2 that describes the flow stress $(\sigma)$ as a function of deformation temperature $(T)$ and strain rate $(\dot{\varepsilon})$ for PM/Wrought dual superalloy can be expressed as:

$$
\dot{\varepsilon}=2.33 \times 10^{28}[\sinh (0.0066 \sigma)]^{4.14} \exp \left(-\frac{780070}{\mathrm{RT}}\right)
$$

It is worth noting that in the established constitutive model of Equation (12), only the effects of deformation temperature and strain rate on flow stress are considered. However, as shown in Figure 3, the flow stress changes with the augmentation of the strain. Moreover, it is well known that the influence of the strain on the deformation activation energy and material constants is significant. In order to more accurately analyze the flow behavior of the PM/Wrought dual superalloy, the material constants $(Q, A, n$, and $\alpha)$ are obtained using above-mentioned method at various strains within the range of $0.05-0.69$ (interval of 0.05). The relationships between $Q, \ln A, n, \alpha$, and true strain for PM/Wrought dual superalloy (Figure 7) can be polynomially fitted, as shown in Equation (13). The polynomial fitting results are presented in Table 1.

$$
\begin{aligned}
& Q=Q_{0}+Q_{1} \varepsilon+Q_{2} \varepsilon^{2}+Q_{3} \varepsilon^{3}+Q_{4} \varepsilon^{4}+Q_{5} \varepsilon^{5} \\
& \ln A=L_{0}+L_{1} \varepsilon+L_{2} \varepsilon^{2}+L_{3} \varepsilon^{3}+L_{4} \varepsilon^{4}+L_{5} \varepsilon^{5} \\
& n=N_{0}+N_{1} \varepsilon+N_{2} \varepsilon^{2}+N_{3} \varepsilon^{3}+N_{4} \varepsilon^{4}+N_{5} \varepsilon^{5} \\
& \alpha=A_{0}+A_{1} \varepsilon+A_{2} \varepsilon^{2}+A_{3} \varepsilon^{3}+A_{4} \varepsilon^{4}+A_{5} \varepsilon^{5}
\end{aligned}
$$

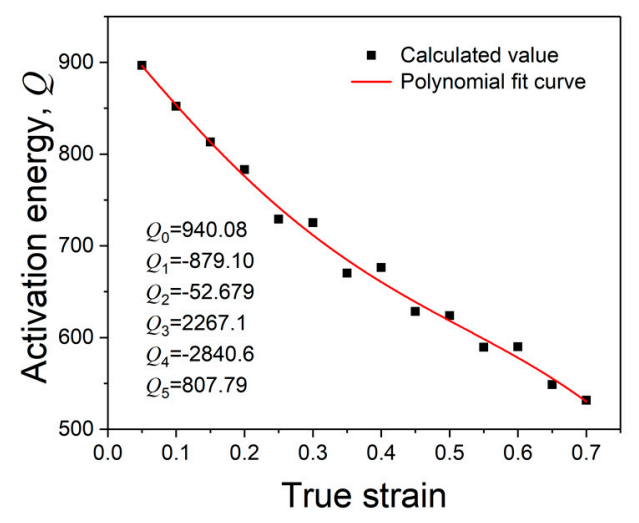

(a)

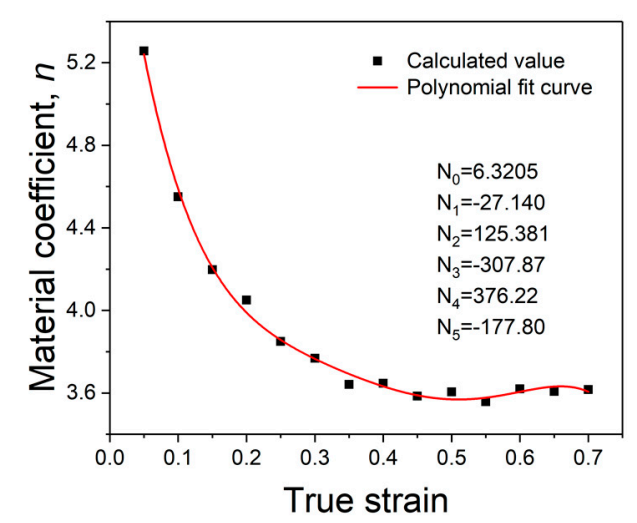

(c)

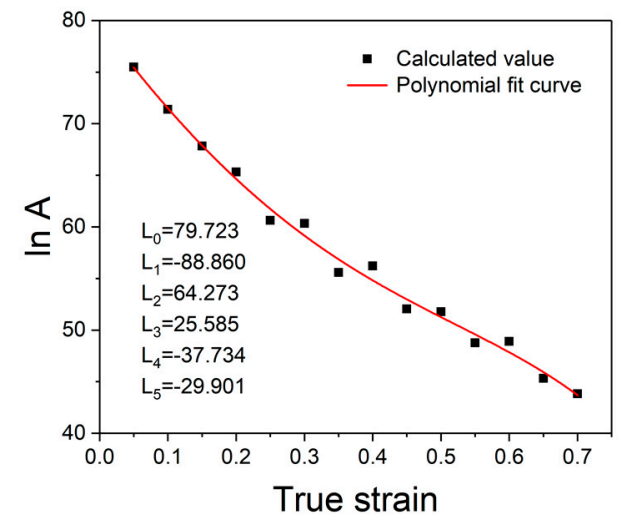

(b)

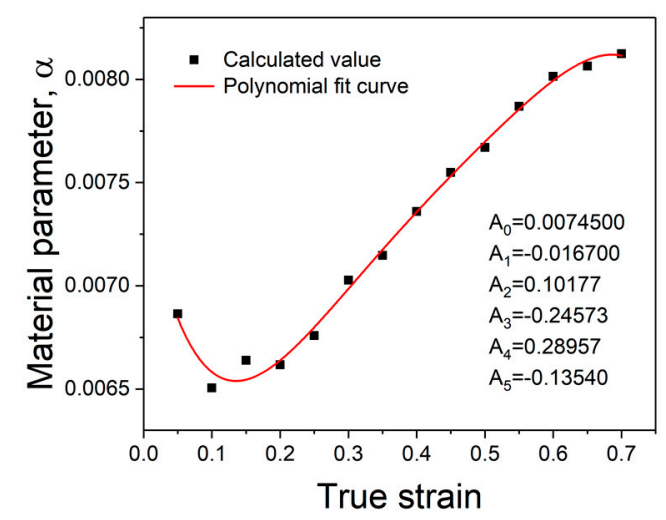

(d)

Figure 7. Relationships between (a) $Q$; (b) $\ln A ;(\mathbf{c}) n$; (d) $\alpha$; and true strain in polynomial fit of the PM/Wrought dual superalloy. 
Table 1. Polynomial fit results of $Q, \ln A, n$, and $\alpha$ of the PM/Wrought dual superalloy.

\begin{tabular}{cccccccc}
\hline $\boldsymbol{Q}$ & Value & $\ln \boldsymbol{A}$ & Value & $\boldsymbol{n}$ & Value & $\boldsymbol{\alpha}$ & Value \\
\hline$Q_{0}$ & 940.08 & $L_{0}$ & 79.723 & $N_{0}$ & 6.3205 & $A_{0}$ & 0.0074500 \\
$Q_{1}$ & -879.10 & $L_{1}$ & -88.860 & $N_{1}$ & -27.140 & $A_{1}$ & -0.016700 \\
$Q_{2}$ & -52.679 & $L_{2}$ & 64.273 & $N_{2}$ & 125.381 & $A_{2}$ & 0.10177 \\
$Q_{3}$ & 2267.1 & $L_{3}$ & 25.585 & $N_{3}$ & -307.87 & $A_{3}$ & -0.24573 \\
$Q_{4}$ & -2840.6 & $L_{4}$ & -37.734 & $N_{4}$ & 376.22 & $A_{4}$ & 0.28957 \\
$Q_{5}$ & 807.79 & $L_{5}$ & -29.901 & $N_{5}$ & -177.80 & $A_{5}$ & -0.13540 \\
\hline
\end{tabular}

Based on the above-mentioned computation, the constitutive equations under different strains can be established. Thus, the predicted-values of flow stress can be calculated for PM/Wrought dual superalloy at various deformation conditions. The comparison between the experimental flow stresses and the predicted flow stresses at a certain strain rate is shown in Figure 8. Obviously, it can be observed that the predicted results are in good agreement with the experimental values, which indicates that the constitutive equations established in this paper are able to provide a higher prediction accuracy of flow stress for the PM/Wrought dual superalloy.

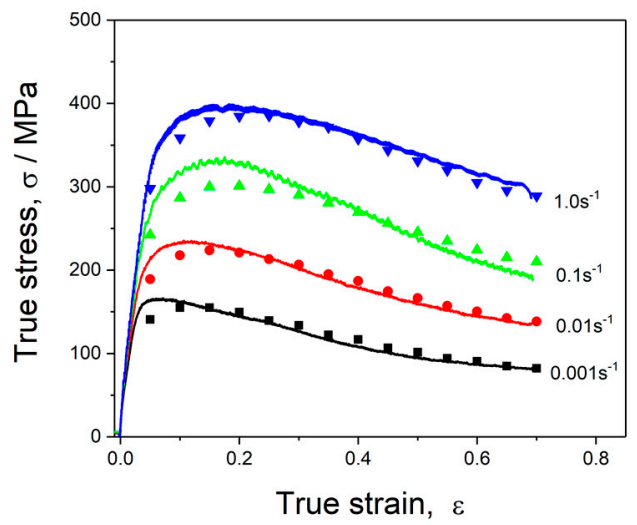

(a)

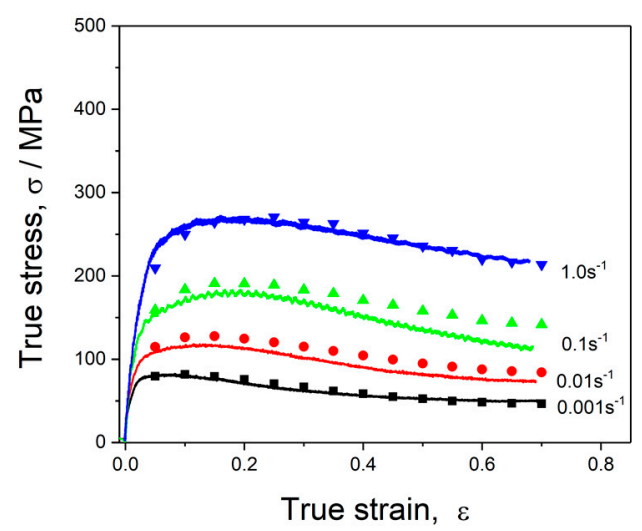

(c)

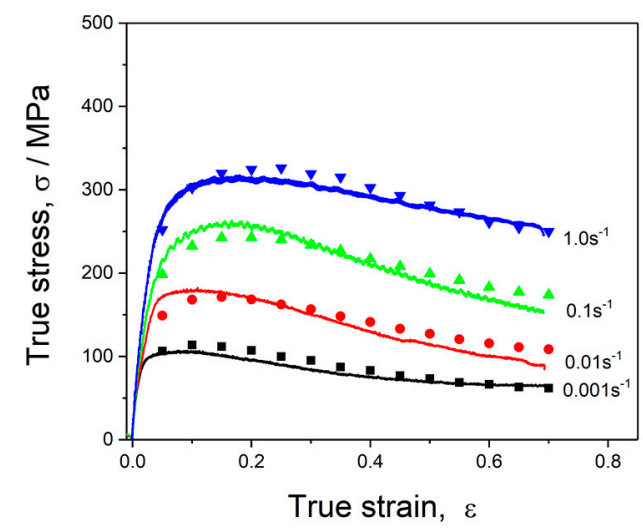

(b)

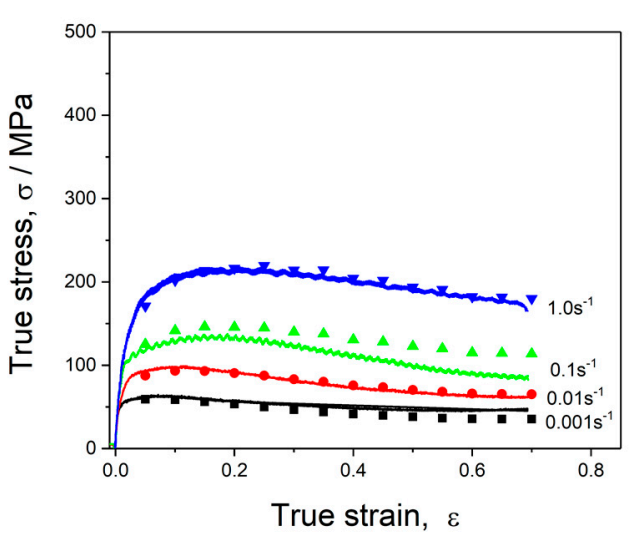

(d)

Figure 8. Cont. 


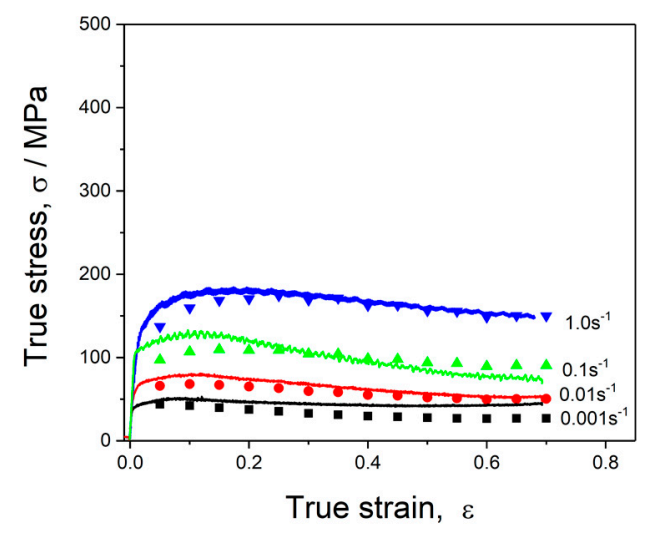

(e)

Figure 8. Comparison between experimental and predicted flow stresses of the PM/Wrought dual superalloy at deformation temperatures of (a) $1020^{\circ} \mathrm{C}$; (b) $1050{ }^{\circ} \mathrm{C}$; (c) $1080^{\circ} \mathrm{C}$; (d) $1110{ }^{\circ} \mathrm{C}$; (e) $1140{ }^{\circ} \mathrm{C}$.

\subsection{Establishment of Processing Map}

The approach of dynamic materials model (DMM) has been widely used to establish processing map [13-15]. Based on the theory of DMM, the work-piece under the hot deformation process can be well regarded as a power dissipating system. The total power dissipation $P$ is assumed to be combination of two complementary parts: $G$ content and $J$ co-content, which can be determined by:

$$
P=\sigma \dot{\varepsilon}=G+J=\int_{0}^{\dot{\varepsilon}} \sigma d \dot{\varepsilon}+\int_{0}^{\sigma} \dot{\varepsilon} d \sigma
$$

where $G$ content denotes the power consumed by the plastic deformation, most of which is released by thermal energy, while the $J$ co-content represents the power dissipation induced by metallurgical evolution during hot deformation, such as DRV, DRX, and phase transformation. When the deformation temperature and strain are constant, the flow stress $(\sigma)$ of work-piece can be represented by the dynamic constitutive equation $\sigma=K \dot{\varepsilon}^{m}$, where $K$ is a material parameter and $m$ is the strain rate sensitivity exponent. Generally, the distribution of power dissipation between $G$ and $J$ is determined by the constitutive flow behavior of metal materials, thus the $G$ content and $J$ co-content can be expressed as:

$$
\begin{gathered}
G=\int_{0}^{\dot{\varepsilon}} \sigma d \dot{\varepsilon}=\int_{0}^{\dot{\varepsilon}}\left(K \dot{\varepsilon}^{m}\right) d \dot{\varepsilon}=\frac{K \dot{\varepsilon}^{m+1}}{m+1}=\frac{\sigma \dot{\varepsilon}}{1+m} \\
J=\int_{0}^{\sigma} \dot{\varepsilon} d \sigma=\int_{0}^{\sigma}(\sigma / K)^{\frac{1}{m}} d \sigma=\frac{K(\sigma / K)^{\frac{1}{m}+1}}{\frac{1}{m}+1}=\frac{m \sigma \dot{\varepsilon}}{1+m}
\end{gathered}
$$

The strain rate sensitivity exponent $m$ can be defined by the ratio of $d J / d G$. For an ideal linear dissipater, the value of $m$ is 1 and the $J$ co-content reaches the maximum value $J_{\max }=\sigma \dot{\varepsilon} / 2$. For a non-linear dissipation process, the efficiency of dissipation $\eta$ is employed to measure the power dissipation capacity of materials during hot deformation, which can be evaluated as:

$$
\eta=\frac{J}{J_{\max }}=\frac{2 m}{1+m}
$$

The power dissipation map can be composed by the variation of $\eta$-value under all hot deformation conditions, which is employed to preliminarily judge certain specific microstructural mechanism may develop during the hot deformation process. Generally, the region with a high $\eta$ value 
corresponds to a preferable processing condition. In this "safe" regime, power dissipates by great microstructure evolution.

In order to avoid the formation of defects during the hot deformation process, on the basis of the maximum rate of entropy production principle, a continuum criterion used to judge the occurrence of flow instability can be obtained, which is shown as the following:

$$
\xi(\dot{\varepsilon})=\frac{\partial \ln [m /(1+m)]}{\partial \ln \dot{\varepsilon}}+m<0
$$

Generally, the negative value of $\xi(\dot{\varepsilon})$ indicates that detrimental deformation mechanism may happen, such as dynamic strain aging, mechanical twinning, adiabatic shear band formation, and the initiation of micro-cracks [16,17], thus flow instability can be forecasted to occur.

The strain rate sensitivity exponent $m$ is a very critical parameter in the forming of plastic materials. Generally, $m$-value is widely associated with deformation mechanism, therefore many investigators have employed diverse means to calculate it $[18,19]$. In addition, some researchers reported that the variety of $m$-values is related to the deformation parameters and microstructural evolution. Ning et al. [20] investigated the hot deformation behavior of P/M nickel-based superalloy, and found the variation of $m$-value is related to the DRX process. Moreover, with the increase of strain, the fraction of the dynamic recrystallized grains increases with the $m$-value. Lin et al. [21] explored the hot tensile deformation behavior of a typical Ni-based superalloy and determined that the studied superalloy has a good necking diffusion and transfer capacity when the strain rate sensitivity exponent $\mathrm{m}$ is relatively high. Liu et al. [22] studied the effect of temperature and strain rate on the workability of the FGH4096 superalloy, and concluded that the values of strain rate sensitivity exponent $m$ present significant variation because of the dissolution of the $\gamma^{\prime}$ phase.

Figure 9 gives the fitted cubic splines for $\log \sigma-\log \dot{\varepsilon}$ at different deformation conditions to calculate the value of the strain rate sensitivity exponent $m$. Apparently, the value of $m$ for PM/Wrought dual superalloy is significantly influenced by the different deformation temperatures and strain rates. Figure 10 presents the variation map of the $m$-value for PM/Wrought dual superalloy, from which the explicit response of $m$-value to strain, strain rate, and deformation temperature can be directly reflected. It can be observed that with the alteration of strain, strain rate and deformation temperature, the strain rate sensitivity exponent $m$ varies irregularly. Remarkably, the $m$-value at the strain of 0.69 and the strain rate of $1.0 \mathrm{~s}^{-1}$ decreases at first as the deformation temperature increases. Then, a minimum $m$-value can be gotten. Finally, the value begins to increase gradually at higher deformation temperatures. It is interesting to note that the minimum $m$-value is gained at $1050{ }^{\circ} \mathrm{C}$, and this temperature is near the recrystallization temperature. The cause of this phenomenon may be well explained by the variation of the grain size.

Figure 11 illustrates the microstructures and the $m$-values of the PM/Wrought dual superalloy deformed at the strain rate of $1.0 \mathrm{~s}^{-1}$. The nuclei of recrystallized grains can be observed at $1050{ }^{\circ} \mathrm{C}$ from Figure 11, which indicates that recrystallization begins to occur, results in the minimum $m$-value appeared. With the deformation temperature increases, the nuclei gradually grow up into equiaxed grains, which leads to the $m$-value at the deformation temperature of $1140{ }^{\circ} \mathrm{C}$ is higher than $1050{ }^{\circ} \mathrm{C}$. Generally, fine grain size is favorable for the sliding of grain boundary, so the alternation of the grain size can provide a reasonable explanation for the variation of strain rate sensitivity exponent $m$ when the deformation temperature increases from 1050 to $1140{ }^{\circ} \mathrm{C}$.

It has been widely accepted that the investigation of power dissipation map is an effective method to optimize hot processing parameters and control microstructural evolution during the hot plastic deformation process. Based on the three-dimensional variations of the $\eta$-value with the strain rate and deformation temperature, the power dissipation map can be constructed under a particular strain. Power dissipation map can be employed to exhibit various regions, which are correlated with particular mechanism of microstructural evolution during the hot plastic deformation process. In this map, the different contours with various efficiency of power dissipation $\eta$ values represent the diverse 
microstructural mechanisms. It is generally considered that the regions with higher $\eta$ values are the optimum hot deformation condition, under which the hot workability could be ameliorated and suitable microstructure can be obtained. Figure 12 gives the response 3D surfaces of the efficiency of power dissipation for PM/Wrought dual superalloy at the true strains of $0.1,0.3,0.5$, and 0.69 . It can be observed from Figure 12 that there are three features shown in the 3D-colormap surface, viz., mountain, valley, and cliff. The efficiency of power dissipation $(\eta)$ shifts among different feature, indicating that the hot workability of PM/Wrought dual superalloy changes evidently with the increasing strain from 0.1 to 0.69 . With further observation, at deformation temperatures ranging from 1110 to $1140{ }^{\circ} \mathrm{C}$, under a relatively small true strain $(0.1$ and 0.3$)$ the $\eta$-value at the strain rate of $1.0 \mathrm{~s}^{-1}$ is lower than at $0.001 \mathrm{~s}^{-1}$, however, which is completely opposite to when there is a high strain ( 0.5 and 0.69$)$. In general, the efficiency of power dissipation $\eta$ related to DRV is about 0.30 , while the value associated with DRX is about $0.30-0.50[23,24]$. Obviously, the efficiency of power dissipation is higher than 0.30 under the deformation condition of $\left(T_{d}: 1100-1140^{\circ} \mathrm{C}, \dot{\varepsilon}: 0.1-1.0 \mathrm{~s}^{-1}\right)$ at large strains. Moreover, the peak efficiency of about 0.55 occurring at $1140^{\circ} \mathrm{C} / 1.0 \mathrm{~s}^{-1}$ in this domain. Therefore, the optimum processing condition of PM/Wrought dual superalloy may be considered under this region in the case of large deformation.

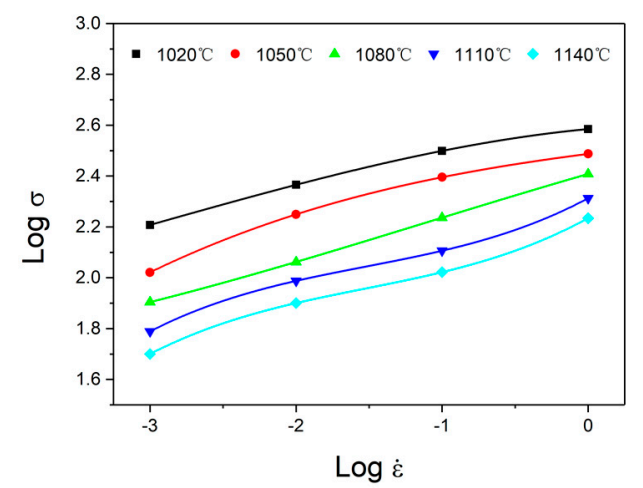

(a)

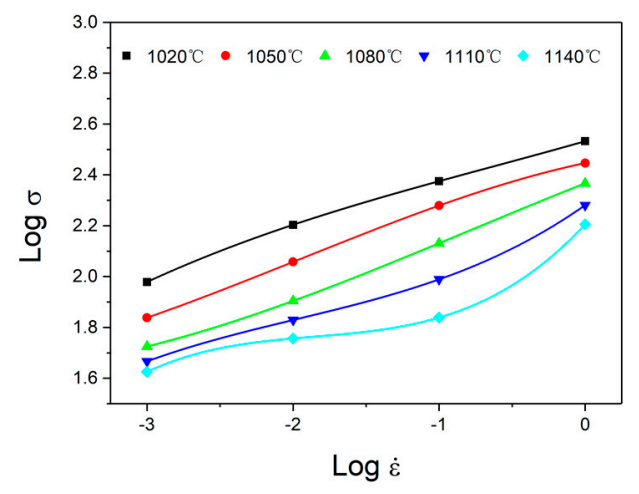

(c)

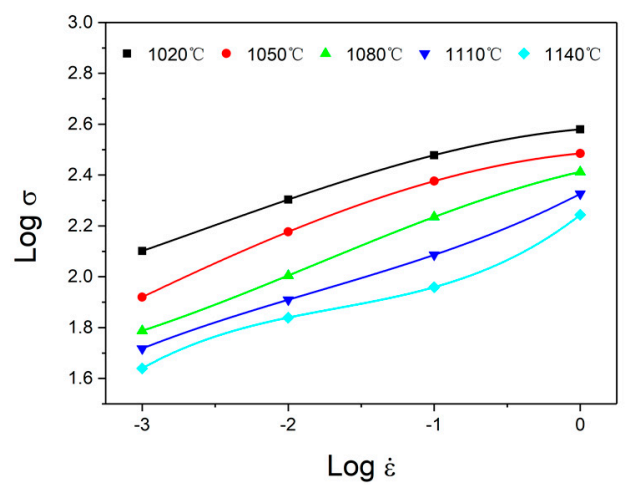

(b)

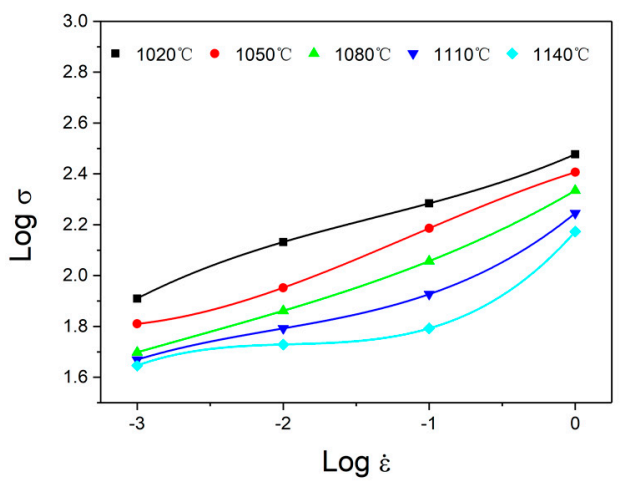

(d)

Figure 9. Relationships between stress and strain rate in log scale of the PM/Wrought dual superalloy at different deformation temperatures as true strains: (a) 0.1 ; (b) 0.3 ; (c) 0.5 ; (d) 0.69 . 


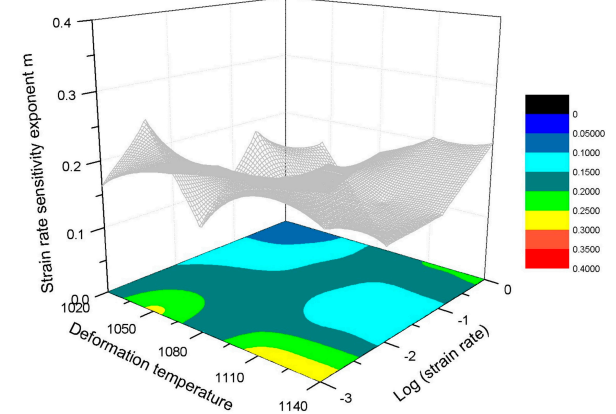

(a)

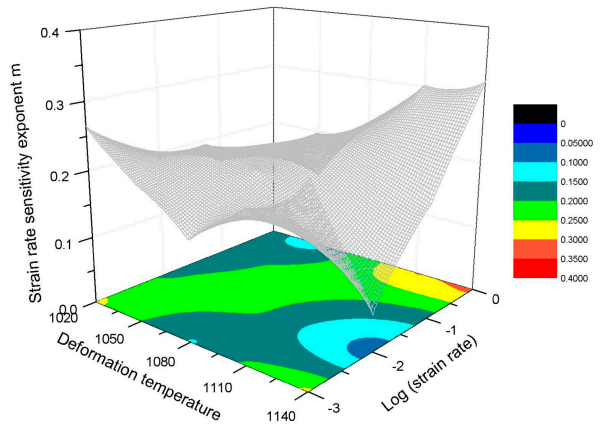

(c)

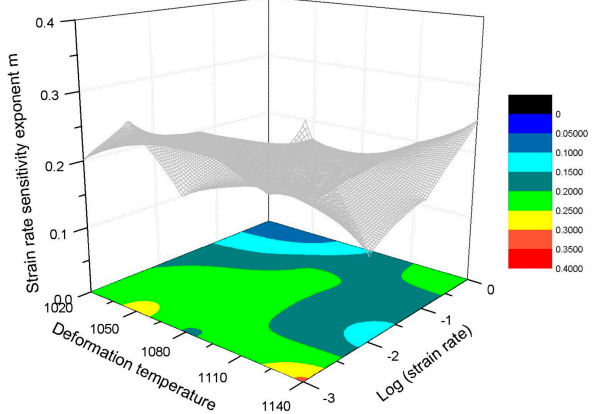

(b)

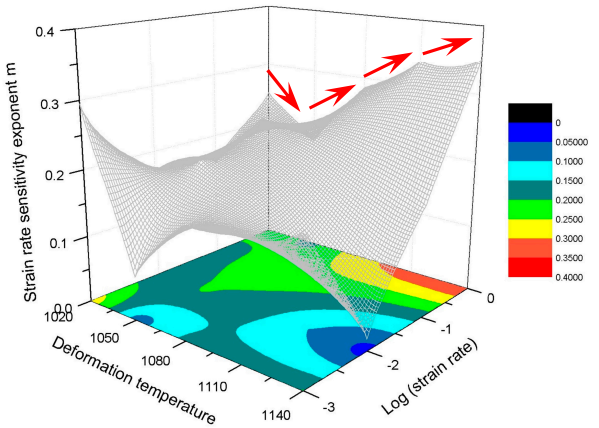

(d)

Figure 10. The response 3D surfaces of $m$-values for the PM/Wrought dual superalloy to deformation temperature and strain rate as true strains: (a) 0.1 ; (b) 0.3 ; (c) 0.5 ; (d) 0.69 .

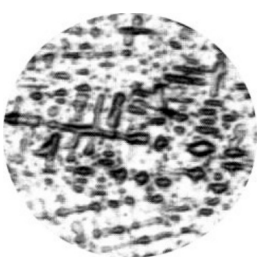

(a)

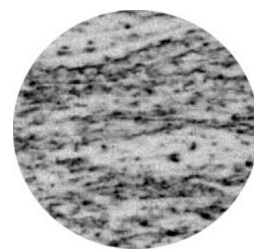

(b)

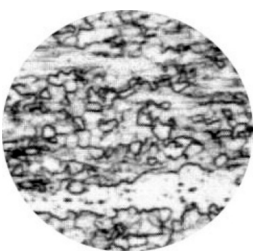

(c)

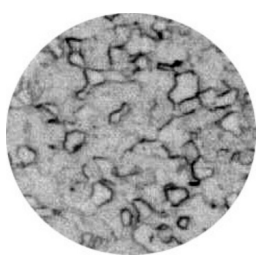

(d)

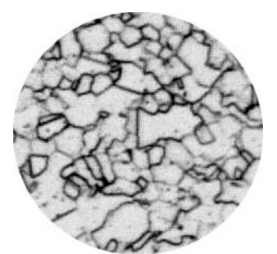

(e)

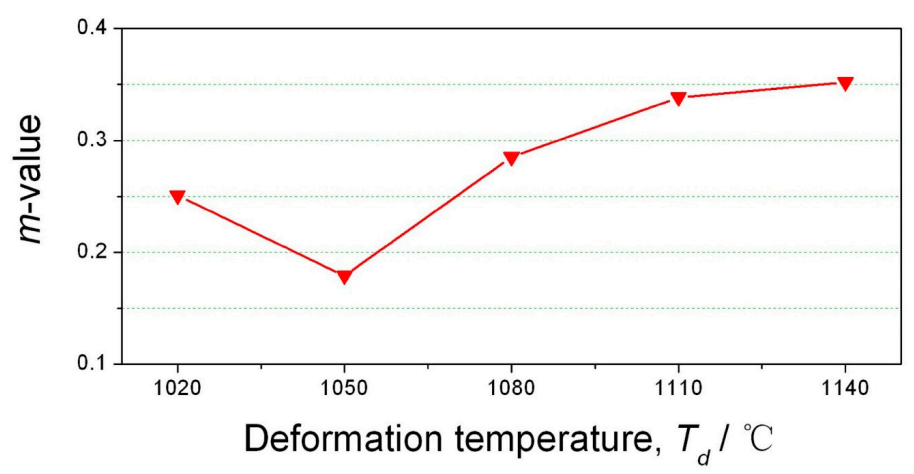

Figure 11. The microstructures and $m$-values of the PM/Wrought dual superalloy processed with the strain rate of $1.0 \mathrm{~s}^{-1}$ at different deformation temperatures of (a) $1020^{\circ} \mathrm{C}$; (b) $1050{ }^{\circ} \mathrm{C}$; (c) $1080{ }^{\circ} \mathrm{C}$; (d) $1110^{\circ} \mathrm{C}$; (e) $1140{ }^{\circ} \mathrm{C}$. 


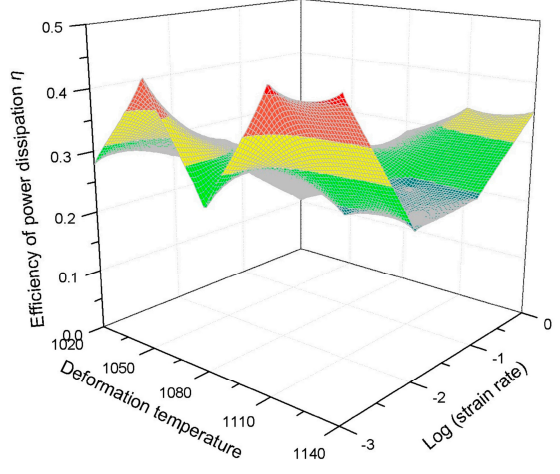

(a)

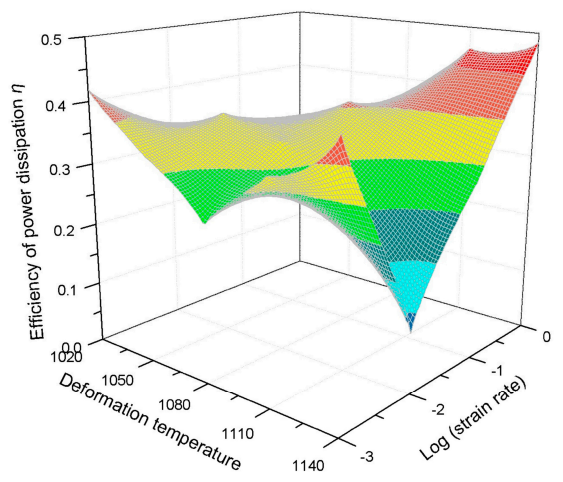

(c)

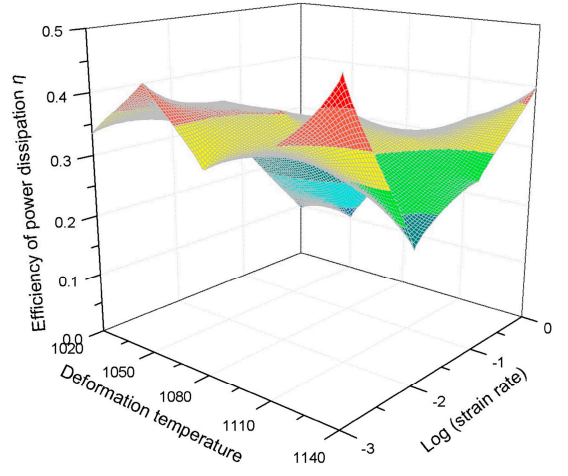

(b)

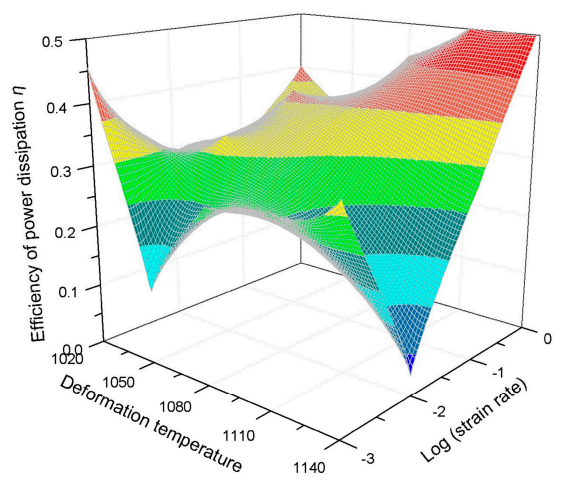

(d)

Figure 12. The response 3D surfaces of the efficiency of power dissipation ( $\eta$ ) for the PM/Wrought dual superalloy to deformation temperature and strain rate as true strains: (a) 0.1 ; (b) 0.3 ; (c) 0.5 ; (d) 0.69 .

\subsection{New Instability Criterion from Power Dissipation Map}

According to the dynamic material model (DMM), different instability criteria have been advanced by Prasad [25], Gegel [26], Malas [27], Murty [28], and Semiatin [29], which are utilized to investigate the hot plastic deformation of metallic materials. In this research, a new approach for finding the instable region from power dissipation map is proposed. Figure 13 schematically illustrates the instability criterion of the PM/Wrought dual superalloy. A local region marked as cliff is shown in Figure 13, where the $\eta$-value distinctly converts from high into low. Subsequently, under the cliff, it can be observed that there is a valley with a lower $\eta$-value. In general, there are some "bottoms" in the valley, in which the value of $\eta$ is less than 0.1. An unstable region can be predicted between the cliff and valley. The flow instability may occur during the hot plastic deformation process when the deformation condition located in this region. It should be noted that the "cliff" and "valley" features are the sufficient conditions of flow instability, but not necessary conditions. As a matter of fact, the occurrence of flow instability is the result of the interaction of many complex factors in the hot plastic deformation process. Therefore, further research is still needed to provide certification of the microstructural mechanism and mathematical equation. 


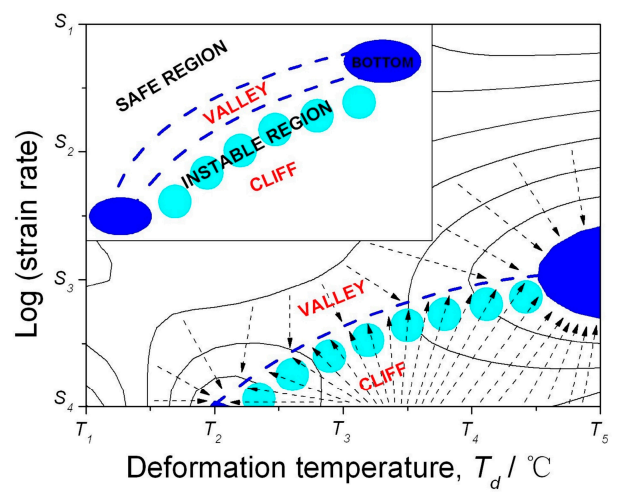

Figure 13. Schematic illustration of the instability criterion for PM/Wrought dual superalloy.

\subsection{Typical Microstructures of PM/Wrought Dual Superalloy Processed After Hot Plastic Deformation}

Figure 14 shows the microstructures of the PM/Wrought dual superalloys that were deformed at different hot compression conditions. Obviously, the deformation temperature and strain rate have great effects on the interface microstructure of the PM/Wrought dual superalloy. Moreover, it can be clearly observed from Figure 14 that these typical microstructures provide the evidence for DRV, DRX, and grain growth. The compression microstructures of the samples at $1020^{\circ} \mathrm{C}$ under different strain rates are shown in Figure 14i-iv. In these microstructures, many grains are elongated in the compression direction and the grain boundaries are irregular. In general, the DRV are difficult to encourage to develop due to the limited deformation activation energy when the deformation temperature is low. When the PM/Wrought dual superalloy deformed at the deformation temperature of $1050{ }^{\circ} \mathrm{C}$ and high strain rates of $0.1-1.0 \mathrm{~s}^{-1}$, the typical microstructures present a distinct feature of DRV. In addition, typical necklace structures could be observed, as shown in Figure 14vi, in which the residual dendrite is entirely surrounded by the recrystallized grains. A typical DRX microstructure is shown at the lower-left domain with the deformation temperatures of $1080-1140{ }^{\circ} \mathrm{C}$ and strain rates of $0.1-1.0 \mathrm{~s}^{-1}$. The distribution of DRX grains and residual dendrite in this domain can be seen. Furthermore, the area fraction of DRX grain increases with deformation temperature, this indicates that the relatively high deformation temperature can accelerate the process of DRX. As shown in the lower-right domain, the residual dendrites are almost totally disappeared at deformation temperatures of $1110-1140{ }^{\circ} \mathrm{C}$ and strain rates of $0.001-0.01 \mathrm{~s}^{-1}$ due to the DRX has occurred fully. Moreover, it is noteworthy that the coarse microstructure exists at this domain. This phenomenon is owing to the grain growth and strengthened phase being coarsened when the samples were deformed at the lower strain rate. So as to obtain the homogeneous microstructure with fine grains and realize a great transition of the welding interface, hot plastic deformation should be processed under the condition of $1140{ }^{\circ} \mathrm{C} / 1.0$ $\mathrm{s}^{-1}$ with the peak efficiency of 0.55 . After hot plastic deformation, the microstructure of welding seam for PM/Wrought dual superalloy was greatly improved, showing equiaxed microstructure. It is noteworthy that there may be some differences in grain size between powder metallurgy superalloy, bonding interface, and wrought superalloy. Therefore, further research focus should be concentrated on microstructural optimization. 


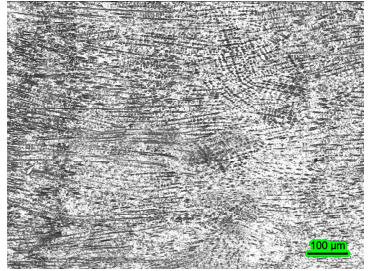

(i)

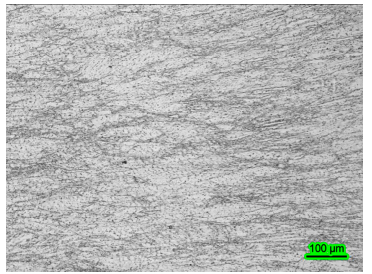

(v)

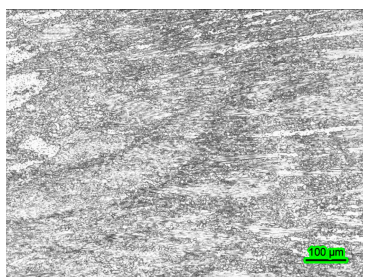

(ix)

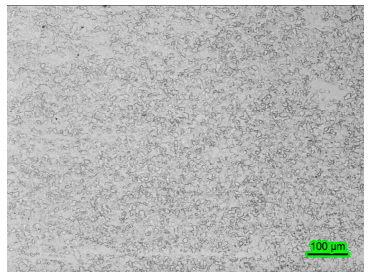

(xiii)

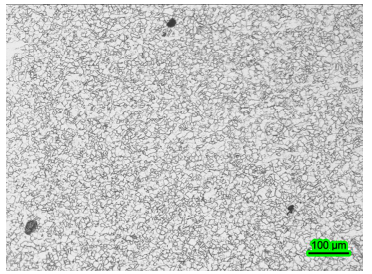

(xvii)

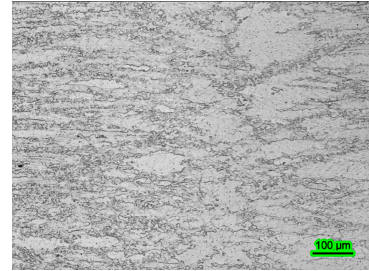

(ii)

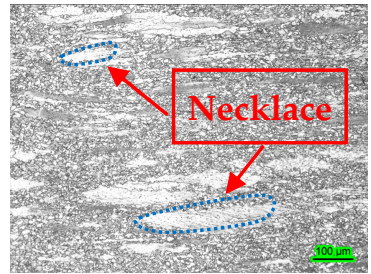

(vi)

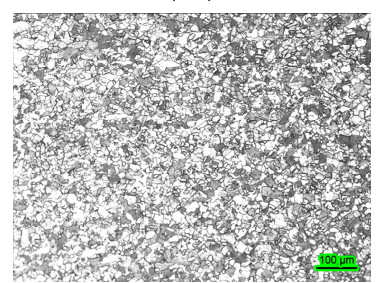

(x)

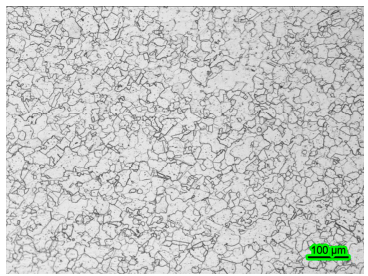

(xiv)

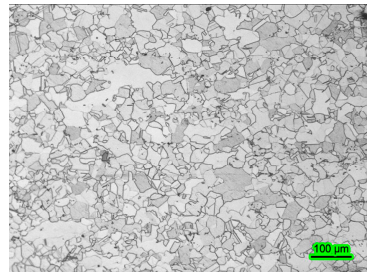

(xviii)

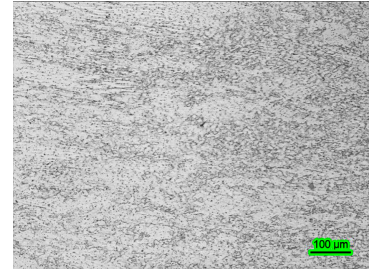

(iii)

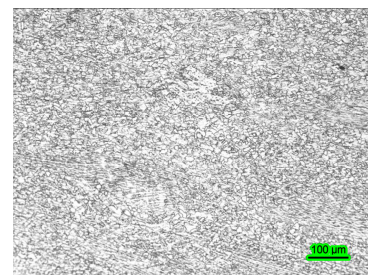

(vii)

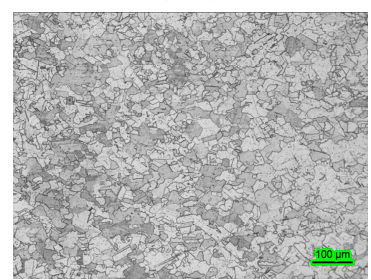

(xi)

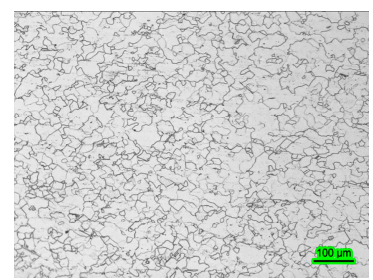

(xv)

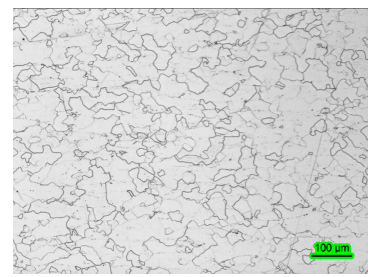

(xix)

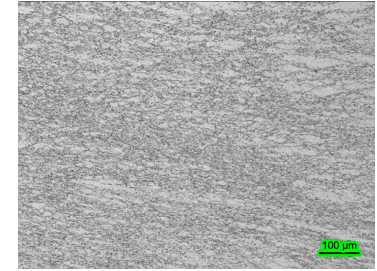

(iv)

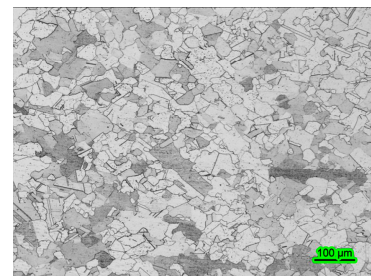

(viii)

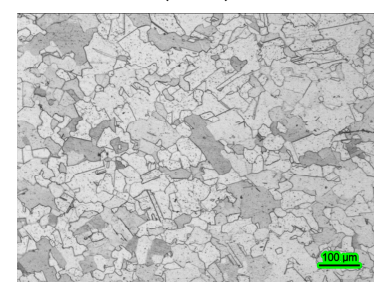

(xii)

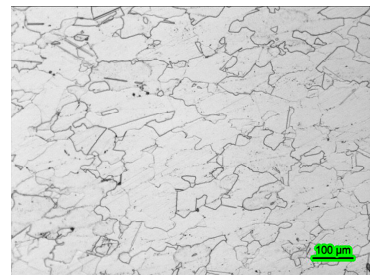

(xvi)

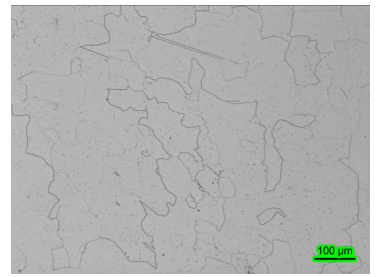

(xx)

Figure 14. Typical microstructures of PM/Wrought dual superalloy processed after hot compression. (i) $1020{ }^{\circ} \mathrm{C} / 1.0 \mathrm{~s}^{-1}$; (ii) $1020^{\circ} \mathrm{C} / 0.1 \mathrm{~s}^{-1}$; (iii) $1020^{\circ} \mathrm{C} / 0.01 \mathrm{~s}^{-1}$; (iv) $1020^{\circ} \mathrm{C} / 0.001 \mathrm{~s}^{-1}$;.(v) $1050{ }^{\circ} \mathrm{C} / 1.0 \mathrm{~s}^{-1}$; (vi) $1050{ }^{\circ} \mathrm{C} / 0.1 \mathrm{~s}^{-1}$; (vii) $1050{ }^{\circ} \mathrm{C} / 0.01 \mathrm{~s}^{-1}$; (viii) $1050{ }^{\circ} \mathrm{C} / 0.001 \mathrm{~s} \mathrm{~s}^{-1}$; (ix) $1080{ }^{\circ} \mathrm{C} / 1.0 \mathrm{~s}^{-1}$; (x) $1080{ }^{\circ} \mathrm{C} / 0.1$ $\mathrm{s}^{-1}$; (xi) $1080^{\circ} \mathrm{C} / 0.01 \mathrm{~s}^{-1}$; (xii) $1080^{\circ} \mathrm{C} / 0.001 \mathrm{~s}^{-1}$; (xiii) $1110^{\circ} \mathrm{C} / 1.0 \mathrm{~s}^{-1}$; (xiv) $1110^{\circ} \mathrm{C} / 0.1 \mathrm{~s}^{-1}$; (xv) 1110 ${ }^{\circ} \mathrm{C} / 0.01 \mathrm{~s}^{-1}$; (xvi) $1110^{\circ} \mathrm{C} / 0.001 \mathrm{~s}^{-1}$; (xvii) $1140{ }^{\circ} \mathrm{C} / 1.0 \mathrm{~s}^{-1}$; (xviii) $1140{ }^{\circ} \mathrm{C} / 0.1 \mathrm{~s}^{-1}$; (xix) $1140{ }^{\circ} \mathrm{C} / 0.01 \mathrm{~s}^{-1}$; (xx) $1140{ }^{\circ} \mathrm{C} / 0.001 \mathrm{~s}^{-1}$.

\section{Conclusions}

The hot deformation behavior and microstructural mechanism of PM/Wrought dual superalloy fabricated by electron beam welding have been deeply investigated at the deformation temperatures of $1020-1140{ }^{\circ} \mathrm{C}$ and strain rates of $0.001-1.0 \mathrm{~s}^{-1}$. Conclusions as below can be summarized from this research: 
(1) PM/Wrought dual superalloy presents the similar flow behavior to that of single alloy. The true stress-strain curves indicate that the deformation temperature and strain rate have a significant effect on the flow behavior of the PM/Wrought dual superalloy.

(2) The apparent activation energy of the PM/Wrought dual superalloy at the strain of 0.2 was determined as $780.07 \mathrm{~kJ} \cdot \mathrm{mol}^{-1}$. The constitutive equation constructed for modeling the hot plastic deformation of PM/Wrought dual superalloy can be expressed as:

$$
\dot{\varepsilon}=2.33 \times 10^{28}[\sinh (0.0066 \sigma)]^{4.14} \exp \left(-\frac{780070}{\mathrm{RT}}\right)
$$

(3) A new approach for finding the instable region from power dissipation map was proposed: the "cliff" and "valley" features are the sufficient conditions of flow instability.

(4) According to the power dissipation map and microstructural characterization, the optimum hot plastic deformation parameter is suggested to be $1140{ }^{\circ} \mathrm{C} / 1.0 \mathrm{~s}^{-1}$ with the peak efficiency of 0.55 for manufacturing the dual-property turbine disc.

Author Contributions: Methodology, B.Z.; investigation, B.Z. and H.Y.; writing-original draft preparation, B.Z. and X.L.; writing — review and editing, Y.N.; funding acquisition, Y.N.

Funding: The work was financially supported by the National Natural Science Foundation of China (Grant No. 51775440) and Fundamental Research Funds for the Central Universities (Grant No. 3102018ZY005).

Conflicts of Interest: The authors declare no conflict of interest.

\section{References}

1. Ning, Y.Q.; Yao, Z.K.; Guo, H.Z.; Fu, M.W. Structural-gradient-materials produced by gradient temperature heat treatment for dual-property turbine disc. J. Alloys Compd. 2013, 557, 27-33. [CrossRef]

2. Cheng, C.; Yu, B.B.; Chen, Z.Y.; Liu, J.R.; Wang, Q.J. Mechanical properties of electron beam welded dissimilar joints of TC17 and Ti60 alloys. J. Mater. Sci. Technol. 2018, 34, 1859-1866. [CrossRef]

3. Zhang, S.L.; Ma, Y.J.; Huang, S.S.; Youssef, S.S.; Qi, M.; Wang, H.; Qiu, J.K.; Lei, J.F.; Yang, R. Temperature-gradient induced microstructure evolution in heat-affected zone of electron beam welded Ti-6Al-4V titanium alloy. J. Mater. Sci. Technol. 2019, 35, 1681-1690. [CrossRef]

4. Vishwakarma, K.R.; Richards, N.L.; Chaturvedi, M.C. Microstructural analysis of fusion and heat affected zones in electron beam welded ALLVAC ${ }^{\circledR} 718$ PLUS $^{\mathrm{TM}}$ superalloy. Mater. Sci. Eng. A 2008, 480, 517-528. [CrossRef]

5. Ning, Y.Q.; Yao, Z.K.; Guo, H.Z.; Fu, M.W. Hot deformation behavior and hot working characteristic of Nickel-base electron beam weldments. J. Alloys Compd. 2014, 584, 494-502. [CrossRef]

6. Qin, C.; Yao, Z.K.; Ning, Y.Q.; Shi, Z.F.; Guo, H.Z. Hot deformation behavior of TC11/Ti-22Al-25Nb dual-alloy in isothermal compression. Trans. Nonferrous Met. Soc. China 2015, 25, 2195-2205. [CrossRef]

7. Chen, X.M.; Lin, Y.C.; Wen, D.X.; Zhang, J.L.; He, M. Dynamic recrystallization behavior of a typical nickel-based superalloy during hot deformation. Mater. Des. 2014, 57, 568-577. [CrossRef]

8. Lin, Y.C.; Wu, X.Y.; Chen, X.M.; Chen, J.; Wen, D.X.; Zhang, J.L.; Li, L.T. EBSD study of a hot deformed nickel-based superalloy. J. Alloys Compd. 2015, 604, 101-113. [CrossRef]

9. Sellars, C.M.; Mctegart, W.J. On the mechanism of deformation. Acta Metall. 1966, 14, 1136-1138. [CrossRef]

10. Kashyap, B.P.; Chaturvedi, M.C. Activation energy for superplastic deformation of in718 superalloy. Scripta Mater. 2000, 43, 429-433. [CrossRef]

11. Briottet, L.; Jonas, J.J.; Montheillet, F. A mechanical interpretation of the activation energy of high temperature deformation in two phase materials. Acta Mater. 1996, 44, 1665-1672. [CrossRef]

12. Zener, C.; Hollomon, J.H. Effect of strain rate upon plastic flow of steel. J. Appl. Phys. 1944, 15, 22-32. [CrossRef]

13. Mehtedi, M.E.; Gabrielli, F.; Spigarelli, S. Hot workability in process modeling of a bearing steel by using combined constitutive equations and dynamic material model. Mater. Des. 2014, 53, 398-404. [CrossRef]

14. Anbuselvan, S.; Ramanathan, G. Hot deformation and processing maps of extruded ZE41A magnesium alloy. Mater. Des. 2010, 31, 2319-2323. [CrossRef] 
15. Lin, Y.C.; Li, L.T.; Xia, Y.C.; Jiang, Y.Q. Hot deformation and processing map of a typical Al-Zn-Mg-Cu alloy. J. Alloys Compd. 2013, 550, 438-445. [CrossRef]

16. Prasad, Y.V.R.K. Processing maps: A status report. J. Mater. Eng. Perform. 2003, 12, 638-645. [CrossRef]

17. Rao, K.P.; Prasad, Y.V.R.K.; Suresh, K. Hot working behavior and processing map of a $\gamma$-TiAl alloy synthesized by powder metallurgy. Mater. Des. 2011, 32, 4874-4881. [CrossRef]

18. Stüwe, H.P.; Les, P. Strain rate sensitivity of flow stress at large strain. Acta Mater. 1998, 46, 6375-6380. [CrossRef]

19. Ghosh, A.K. On the measurement of strain-rate sensitivity for deformation mechanism in conventional and ultra-fine grain alloys. Mater. Sci. Eng. A 2007, 463, 36-40. [CrossRef]

20. Ning, Y.Q.; Yao, Z.K.; Guo, H.Z.; Fu, M.W.; Li, H.; Xie, X.H. Investigation on hot deformation behavior of P/M Ni-base superalloy FGH96 by using processing maps. Mater. Sci. Eng. A 2010, 527, 6794-6799. [CrossRef]

21. Lin, Y.C.; Deng, J.; Jiang, Y.Q.; Wen, D.X.; Liu, G. Hot tensile deformation behaviors and fracture characteristics of a typical Ni-based superalloy. Mater. Des. 2014, 55, 949-957. [CrossRef]

22. Liu, Y.H.; Ning, Y.Q.; Yang, X.M.; Yao, Z.K.; Guo, H.Z. Effect of temperature and strain rate on the workability of FGH4096 superalloy in hot deformation. Mater. Des. 2016, 95, 669-676. [CrossRef]

23. Ning, Y.Q.; Yao, Z.K.; Li, H.; Guo, H.Z.; Tao, Y.; Zhang, Y.W. High temperature deformation behavior of hot isostatically pressed P/M FGH4096 superalloy. Mater. Sci. Eng. A 2010, 527, 961-966. [CrossRef]

24. Liu, Y.H.; Ning, Y.Q.; Yao, Z.K.; Fu, M.W. Hot deformation behavior of the 1.15C-4.00Cr-3.00V-6.00W-5.00Mo powder metallurgy high speed steel. Mater. Des. 2014, 54, 854-863. [CrossRef]

25. Doraivelu, S.M.; Gegel, H.L.; Gunasekera, J.S.; Malas, J.C.; Morgan, J.T.; Thomas, J.F. A new yield function for compressible $\mathrm{p} / \mathrm{m}$ material. Int. J. Mech. Sci. 1984, 26, 527-535. [CrossRef]

26. Collings, E.W.; Gegel, H.L. A physical basis for solid-solution strengthening and phase stability in alloys of titanium. Scripta Metall. 1973, 7, 437-443. [CrossRef]

27. Malas, J.C.; Seetharaman, V. Using material behavior models to develop process control strategies. JOM 1992, 44, 8-13. [CrossRef]

28. Murty, S.V.S.N.; Rao, B.N.; Kashyap, B.P. Instability criteria for hot deformation of materials. Int. Mater. Rev. 2000, 45, 15-26. [CrossRef]

29. Semiatin, S.L.; Seetharaman, V.; Weiss, I. Hot workability of titanium and titanium aluminide alloys-an overview. Mater. Sci. Eng. A 1998, 243, 1-24. [CrossRef] 